patients undergoing surveillance correlated with their ADRs and PRRs during colonoscopies in a non-surveillance cohort. Therefore, we suggest that all surveillance colonoscopies are performed by endoscopists consistently achieving BSG colonoscopy KPI minimum standards.

\section{PTH-049 AUDIT OF 27 YEARS OF ENDOSCOPY PRACTICE AT THE UNIVERSITY COLLEGE HOSPITAL, IBADAN, NIGERIA}

Samuel Olawale Ola*, Kolawole Oluseyi Akande, Christopher B Summerton. University College Hospital, Ibadan Nigeria, Ibadan, Nigeria

\subsection{6/gutjil-2019-BSGAbstracts.74}

Introduction Endoscopy is an important and useful invasive procedure in patient management and it is rapidly evolving requiring regular update. Hence the need to audit the endoscopic practice in a low economic clime such as Nigeria to ensuring standardization of the procedure towards better patient management, training and research.

Methods The study was a retrospective analysis of the record of endoscopic procedures carried out the Endoscopy Suites of Nigeria's premiere University College Hospital, Ibadan from 1992 to 2018. It involved a review of the biodata of the patients, types of endoscopy procedures carried out versus patient population, experience of the mentor and mentee endoscopists, availability of equipment for endoscopy, leakage testing and therapy, disinfection, storage, report software and other resources towards patient care.

Results From table 1, a total of 7050 patients underwent endoscopy between 1992 and 2018 with 71.4\% of the subjects had GIT procedures. Although GIT endoscopy started in 1978, it was not until 1992 that a record of the procedures was commenced with 4 procedures carried out in 1992 which has grown exponentially yearly to 715 procedures in 2018. Only one consultant GIT endoscopist was available in 1992 and this increased to 8 in 2018. The Endoscopy practice also had 7 Consultant Bronchoscopists and 8 Laryngoscopists at 2018 although the practice has trained 78 trainees with less than 10 endoscopies during training but gained further experience during consultancy practice.

The male female ratio of all the patients for the 7050 procedures (9 Paediatric patients) from 1992 to 2018 is 6:5 with mean age of $50.3 \pm 17.7$ years and age range of 5 to 88 years. The predominant age group of all patients was 40-50 years age group accounting for $15.5 \%$. The procedures were mostly diagnostic with $47.5 \%$ of the patients for upper GIT studies. It is of saddened note that bronchoscopy service has stopped in the 2018 principally due to ageing bronchoscope. In spite of the limited and basic equipment available, the centre ran two endoscopic - pathology workshops in 2007 and 2014 with 50 nurses and 40 doctors at attendance. With the centre serving the whole West Africa subregion, the centre lacked endoscopy report system, facilities for therapeutic endosccopy including ERCP and endoscopy ultrasonography.

Conclusions Although, the centre had been carrying out endoscopy procedures over three decades, this has been predominantly diagnostic endoscopy with limited trainee exposure. Hence there is a need for standardization endoscopy practice amidst other requirements for uplift in endoscopy services, training and research to augment patient care.

Abstract PTH-049 Table 1 Pattern of procedures carried out on patients for Endoscopy at University College Hospital, Ibadan; Nigeria

\begin{tabular}{|c|c|c|c|c|c|}
\hline Procedures & 1992-2017 & 2018 & total & & $\%$ \\
\hline Diagnostic & 2900 & 448 & 3348 & & 47.5 \\
\hline Upper GIT & 1201 & 252 & 1453 & & 20.6 \\
\hline Colonoscopy & 206 & 15 & 221 & & 3.1 \\
\hline Sigmoidoscopy & 2 & 0 & 2 & & $2.8 \times 10^{-4}$ \\
\hline ERCP & 8 & 0 & 8 & & 0.1 \\
\hline Proctoscopy & 4317 & 715 & 5032 & & 71.4 \\
\hline \multicolumn{6}{|l|}{ Subtotal } \\
\hline Laryngoscopy & 750 & 42 & 792 & & 11.2 \\
\hline Bronchoscopy & 89 & 0 & 89 & & 1.3 \\
\hline Subtotal & 5156 & 757 & 5913 & & 83.9 \\
\hline No record & 1137 & 0 & 1137 & & 16.1 \\
\hline Total & 6197 & 757 & 7050 & & 100 \\
\hline \multirow[t]{2}{*}{ Therapeutic } & Variceal banding & Polypectomy & & PEG & \\
\hline & 16 & 1 & & 1 & \\
\hline No of procedures & GIT & Bronchoscopy 3 & & ENT & \\
\hline Mentors $>300$ & 8 & 4 & & 2 & \\
\hline$<110$ & 3 & 4 & & 7 & \\
\hline Mentees < 10 & 19 & & & 55 & \\
\hline Equipment Present & \multicolumn{5}{|c|}{ Leakage tester, Manual disinfection, Urea Breath test kit, Heater probe, Video-endoscopy with HDI, Vital Scopes } \\
\hline Year & $1992-2000$ & $2001-2010$ & $2011-2$ & & \\
\hline No of patients & 211 & 2555 & 428 & & \\
\hline Ratio & 1 & 12 & 20 & & \\
\hline
\end{tabular}

